Cadernos de Clio, Curitiba, v. 12, nº. 1, 2021

\title{
"UM PÉ NA COZINHA": ENTREVISTA COM TAÍS DE SANT'ANNA MACHADO
}

Heloisa Motelewski ${ }^{1}$
Rafaela Zimkovicz

\section{Apresentação}

Na obra Pensamento Feminista Negro: Conhecimento, Consciência e a Política do Empoderamento, a socióloga Patricia Hill Collins conceitua as lentes de interpretação da realidade nas Ciências Sociais como sendo, simultaneamente, sistemáticas de poder e fontes de significação e produção de sujeitos do presente, dadas as suas influências para o questionamento ou a conservação de estruturas políticas e sociais existentes. Nesse cenário, a formulação e o emprego prático de teorias analíticas que tomam em conta as experiências, enquanto sujeitos socialmente situados pelo aparato de racialização e gênero das configurações coloniais do ocidente, de mulheres negras pode ser entendida como um mecanismo chave para o estabelecimento de novas dinâmicas de poder, reconhecimentos agenciais e

1 Graduanda do $3^{\circ}$ período em História (Licenciatura/Bacharelado) pela Universidade Federal do Paraná (UFPR). É integrante bolsista do PET História UFPR e orientanda da Prof ${ }^{a}$. Dr ${ }^{\mathrm{a}}$. Renata Senna Garraffoni no Programa de Iniciação Científica (PIBIC) da mesma instituição. Email para contato: heloisamotelewski@gmail.com. Endereço para o Currículo Lattes: http://lattes.cnpq.br/7022532050657480.

2 Graduanda do $5^{\circ}$ período em História (Licenciatura/Bacharelado) pela Universidade Federal do Paraná (UFPR). É membro bolsista do PET História UFPR e orientanda da Prof ${ }^{a}$. Dr ${ }^{\mathrm{a}}$. Priscila Piazentini Vieira no Programa de Iniciação Científica (PIBIC) da mesma instituição. Email para contato: rzimk@hotmail.com. Endereço para o Currículo Lattes: http://lattes.cnpq.br/6240682986499832. 
justiça social, em um movimento que interliga as realidades do passado à contemporaneidade. Tais dimensões temporais ficam transversalizadas à medida que leituras epistemicamente engajadas com os mecanismos de análise dos feminismos negros levam a um compromisso de leitura crítica das temporalidades pregressas, capazes de problematizar modos produtivos e relacionais fundantes das produções subalternizadas de sujeitos, mas, conjuntamente, contestar, pelo potencial de tensionamento dos paradigmas de autoridade historicamente construídos, as representações silenciadoras das trajetórias de existência de populações negras, indígenas, imigrantes e de diversidade de gênero e sexualidade frente aos parâmetros de masculinismo branco cisheterossexual. Nessa linha, a transformação do futuro depende de uma atuação corrente e da alteração das bases de valorização histórico-cultural para a formação de sujeitos da atualidade, o que prescinde, por sua vez, de um olhar politizado ao passado, dependente, muitas vezes, de um fazer falar das fontes históricas, ato definido pela pensadora Saidyia Hartman como uma "indisciplinarização da História”.

Pensando a abrangência das questões epistêmicas no tocante à prática historiográfica, bem como seus impactos sobre o ensino e sobre a divulgação da História, o grupo PET História UFPR teve a honra de receber a recém-doutorada Taís de Sant'Anna Machado para uma de suas edições de Ciclo de Palestras. Partindo de sua tese doutoral, agora disponibilizada no repositório da $\mathrm{UnB}^{3}$, cujo tema central desenvolve-se desde uma nova

\footnotetext{
3 A tese pode ser acessada na íntegra por meio do seguinte endereço: https://repositorio.unb.br/handle/10482/42205. Recomendamos sua leitura para que conheçam com mais detalhes o primoroso trabalho de nossa entrevistada.
} 
perspectiva sobre o trabalho exercido por mulheres negras nas esferas da produção alimentar, sua fala foi de enorme contribuição para pensar as referências históricas e as permanências atuais dessas questões. Realizado ao vivo ${ }^{4}$, o evento se mostrou uma oportunidade imperdível para a articulação das propostas de Pesquisa e Extensão que regem o Programa de Educação Tutorial (PET), estabelecendo diálogos interessantes entre a produção acadêmica e o público externo à universidade. Assim, esperamos ter contribuído para a construção de uma relação de conectividade entre as problemáticas suscitadas pelo trabalho de nossa convidada e a todes que nos assistiram, fomentando reflexões desde questões levantadas ao decorrer de sua apresentação e do posterior debate.

Em paralelo à organização desse dia de palestra, nos animamos com a possibilidade de poder entrevistá-la, ao que a agradecemos enormemente por ter mantido nossa parceira nesses momentos. Desse modo, dando continuidade à temática da produção alimentar, mas desmembrando algumas questões outras, mais específicas de sua tese, nos dedicamos a ponderar, essencialmente, sobre os espaços de construção do conhecimento, seja em seus caracteres acadêmicos sociológicos ou historiográficos. Para além disso, buscamos produzir reflexões sobre questões sociais brasileiras, perpassando perspectivas históricas e contemporâneas. Tendo isso em vista, ressaltamos, ainda, que as questões que se seguem foram postas à nossa

\footnotetext{
${ }^{4} \mathrm{O}$ evento encontra-se disponível no canal do grupo na plataforma Youtube, tanto o primeiro quanto o segundo dia de palestras. $\mathrm{O}$ acesso à apresentação e aos debates referentes ao trabalho da Dra. Taís de Sant'Anna Machado pode ser feito através deste link: https://www.youtube.com/watch?v=94G8E0PD5is.
} 
Cadernos de Clio, Curitiba, v. 12, $n^{\circ} .1,2021$

entrevistada logo após a nosso encontro no evento, sendo respondidas de forma remota. Com elas, almejamos, então, aprofundar alguns dos temas tratados tanto em sua fala quanto em sua produção escrita, pensando, como ponto fundamental, a possibilidade de se apontar para a complexidade, a proficuidade e a necessidade da continuidade de trabalhos como o seu. Afinal, há urgência para a permanência de olhares mais atentos às opressões dirigidas às mulheres negras. Apenas por esse modo, e abrangendo minuciosamente os mais diversos campos da sociedade, acreditamos ser possível a construção de uma perspectiva analítica que se atente para as potencialidades das interseccionalidades na agência da violência e da resistência.

Anexo I: Capa da tese

“Um Pé na Cozinha”: uma análise sócio-histórica do trabalho de cozinheiras negras no Brasil, produzida pela artista Daiely Gonçalves no ano de 2021.

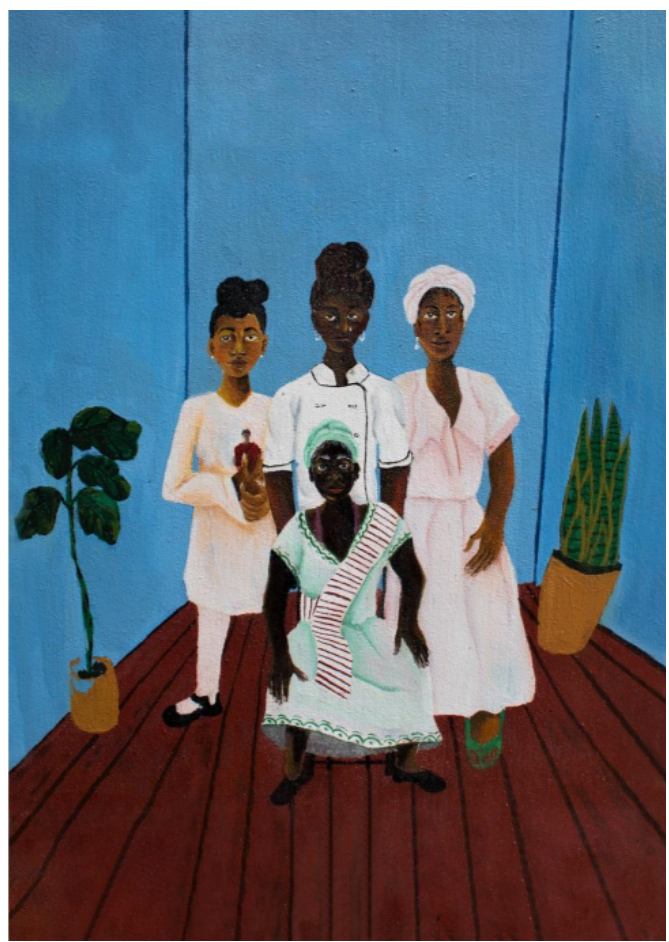


[Equipe Editorial]: Na introdução de seu trabalho, você faz alguns comentários de como a sua atuação em uma Pandemia afetou suas formas de perceber as suposições de neutralidade das Ciências Sociais, assim como sua orientação perspectiva em relação às questões da vivência de mulheres negras na sociedade brasileira. Assim, gostariamos de saber se poderia falar um pouquinho mais sobre essa questão. Então, como você observa o impacto das decorrências pandêmicas sobre sua percepção acerca das narrativas históricas e das epistemologias dos campos das ciências humanas?

[Taís de Sant'Anna Machado]: Minha crítica ao ideal de neutralidade da pesquisa em Ciências Sociais é anterior à pandemia, e sempre me fez refletir sobre como as sensibilidades de meu processo de produção de conhecimento e os acessos que tive em campo foram impactados pelo fato de que sou uma mulher negra. Mas as condições a que fomos forçados a viver durante esse momento histórico me fez [sic] enxergar como essa neutralidade parecia ainda mais ultrapassada. Um dos motivos mais evidentes para a construção dessa percepção foi pensar como as pessoas foram impactadas pelas condições de vida impostas pela pandemia de diferentes formas e como a estrutura social racializada, de classe e de gênero teve e tem impacto sobre as diferentes leituras que fazem do mundo neste momento (inclusive, acredito que a análise da produção do campo de Ciências Sociais durante este período considerando esta questão seria bastante profícua). De modo complementar, em relação ao meu trabalho, 
Cadernos de Clio, Curitiba, v. 12, $n^{\circ} .1,2021$

especificamente, observar de que modo as condições de exclusão social e econômica de sobrevivência da população negra que trato na tese tem se tornado ainda mais insustentáveis durante a pandemia, aliado ao fato de que as notícias sobre as mortes evitáveis de diversas cozinheiras negras, expostas ao vírus pelos patrões que voltavam do exterior, não paravam de chegar, evidenciam como, mesmo em uma situação de calamidade, essa mesma estrutura desigual se mantém e se atualiza. Assim, a ideia de neutralidade parecia ainda mais descabida e, durante o processo de escrita da tese, foi minha intenção marcar que maneira a pandemia teve efeitos específicos sobre a pesquisadora (que escrevia de uma vala cada vez mais funda), o contexto que analisava e as mulheres que eram o tema da pesquisa.

[E. E.]: Um outro ponto que nos chama muito a atenção nessas partes introdutórias de sua tese é a referência à opressão exercida pelas forças estatais e elitistas desde a interseccionalidade de raça e gênero, criando, por essa forma, imagens estereotipadas sobre supostos modelos de atuação da feminilidade negra. Diante disso, nos parece necessário refletir sobre as formas de colocação dessas ideologias sociais de inferiorização e marginalização como fatores "naturais" da vida social brasileira. Assim, perguntamos: de que forma você nota a naturalização, ou até mesmo a "romantização", do papel subalternizado atribuído às mulheres negras na vida prática a partir desse histórico em que se veem comumente atreladas às atividades domésticas e culinárias? 
[Taís de Sant'Anna Machado]: Um dos pontos mais importantes da tese é observar como a imagem da mãe preta cozinheira é um dos fundamentos mais importantes para a sustentação da ideologia da democracia racial no Brasil, e de como ela se constrói especialmente no início do século XX em obras como as de Gilberto Freyre ou Monteiro Lobato (que, não coincidentemente, são consideradas centrais para o campo de estudos de alimentação). Neste sentido, Tia Nastácia, da série de literatura infantil "O Sítio do Picapau Amarelo", é um dos exemplos mais bem acabados dessa narrativa, que tem como projeto construir uma ideia de harmonia racial como característica fundante da sociedade brasileira. O conceito de "imagem de controle", cunhado pela socióloga negra estadunidense Patricia Hill Collins (2019), é central para revelar o fato de que essas "caricaturas têm o objetivo de naturalizar as condições precárias e violentas de trabalho de cozinheiras negras e tentar ocultar a história contínua de sua resistência" (MACHADO, 2021: 26). Como também defendo na tese, as características subservientes e passivas desse estereótipo de mulheres negras construído por homens brancos “(...) naturalizam e estetizam a intimidade monstruosa da exploração do trabalho de mulheres negras e as condições do genocídio social e econômico a que foram submetidas" (MACHADO, 2021: 126). Como observado por Kimberly Wallace-Sanders (2008), ao analisar a construção da figura da mammy nos Estados Unidos, ela funciona como uma "distração", que tem como objetivo manter a posição social e as condições confortáveis de vida das elites e classes médias no pós-abolição. Para tanto, mantém mulheres negras nas piores condições de vida e de 
trabalho, como observa Lélia Gonzalez analisando as políticas de exclusão do mercado de trabalho brasileiro na segunda metade do século XX, e de que maneira são influenciadas por esses estereótipos: “Aquele papo do 'exige-se boa aparência', dos anúncios de empregos, a gente pode traduzir por: 'negra não serve'. Secretária, recepcionista de grandes empresas, balconista de butique elegante, comissária de bordo, etc. e tal, são profissões que exigem contato com o tal público 'exigente' (leia-se: racista). Afinal de contas, para a cabeça desse 'público', a trabalhadora negra tem que ficar no 'seu lugar': ocultada, invisível, "na cozinha", (GONZALES, 2018: 129).

[E. E.]: Nessa mesma linha, de reflexão sobre as naturalizações dos estereótipos das mulheres negras, gostaríamos de chamar a atenção para a figura da figura maternal, doméstica e eminentemente culinária das mulheres. Nesse escopo, você acredita que exista alguma forma de respaldo teórico do mito da 'democracia racial' sob essa imagem da mãe preta cozinheira? Se sim, por qual modo você concebe sua estruturação discursiva, especialmente apreendendo a sua exponencialidade quando tratadas as questões de gênero?

[Taís de Sant'Anna Machado]: Como respondi na questão anterior, a figura da mãe preta cozinheira é certamente central para essa narrativa. A imagem da trabalhadora negra afetuosa, subserviente e grata a seus patrões brancos é um dos fundamentos da ideia de que a "democracia racial" marcou a construção da sociedade brasileira. Trabalhos recentes no campo da 
História (TELLES, 2012) que tem como foco a história de mulheres negras, têm mostrado reiteradamente que a figura da trabalhadora negra que permanece junto à família branca por "amor" ou "lealdade" nunca existiu na proporção defendida por esta narrativa de harmonia racial (se um dia sequer existiu). No momento em que trabalhadoras negras puderam se movimentar em busca de melhores condições de trabalho, elas sempre o fizeram. Isto é apenas um reflexo das condições precárias, violentas e miseravelmente remuneradas a que foram (e têm sido) submetidas nas cozinhas - condições que o estereótipo busca encobrir, mas que os registros históricos revelam.

[E. E.]: Nas seções iniciais de sua tese, você explica os direcionamentos metodológicos aplicados, enfatizando a adesão à perspectiva interseccional de forma heurística e remetendo ao estabelecimento de diálogos conceituais e epistemológicos entre teóricas negras diaspóricas como Lélia Gonzalez, Patricia Hill Collins e Kimberle Crenshaw, todas vinculadas, em diferentes contextos e sob abordagens nuançadas, à defesa da percepção transversalizada das categorias produtoras de hierarquizações de sujeitos na contemporaneidade. Como desenvolvido na introdução, são latentes essas conexões entre produções de práxis feminista negra dos Estados Unidos e do Brasil devido às disrupções da colonialidade escravista que atravessam o percurso de formação social de ambos os países. Entre 2019 e 2020, você realizou um periodo de Doutorado Sanduiche na Brown University (Rhode Island, EUA), sob a 
orientação da Profa. Dr ${ }^{a}$ Keisha-Khan Perry (pesquisadora da área de Antropologia com experiências acerca de ativismos de mulheres negras, feminismos negros, direitos e cidadania, desenvolvidas em países como México, Brasil e Jamaica, além dos Estados Unidos em si), certo? Poderia comentar sobre os impactos dessa etapa de sua formação para a identificação e a tematização dos círculos epistêmicos conformados nos contextos diaspóricos por pensadoras feministas negras?

[Taís de Sant'Anna Machado]: O período como pesquisadora visitante no Departamento de Estudos da Diáspora Africana da Brown University, sob a orientação da professora Keisha-Khan Perry (2013), foi fundamental para entender os contornos mais amplos das questões de raça, gênero e classe que eu analisava e as conexões entre as vivências de cozinheiras negras na Diáspora. A experiência da professora Keisha-Khan em estabelecer relações entre as condições de vida e as formas de ativismo de mulheres negras em diferentes países e sua generosidade em compartilhar seu olhar sobre as minhas questões de pesquisa foram cruciais para que a tese se tornasse um trabalho mais robusto do que eu havia planejado inicialmente. Além disso, o fato de que estava em um Departamento de Estudos da Diáspora Africana, onde pude conhecer o trabalho de professores como Anani Dzidzienyo (1970) e de outros jovens pesquisadores que estudavam temas diversos no contexto da Diáspora, também teve impacto sobre o olhar teórico de caráter diaspórico que marcou a produção da tese, fundada especialmente na teoria social crítica feminista negra dos Estados Unidos e do Brasil. 
[E. E.]: Lendo o primeiro capítulo de "Um pé na cozinha...", torna-se gritante o magistral e delongado caminho de pesquisa e revisão historiográfica que você realizou para situar as condições de trabalho e os estigmas no entorno do exercício de atividades culinárias por mulheres negras no Brasil desde o período colonial, o que é trazido à tona tanto pelas críticas contundentes ao teor racista e romantizador de relatos literários e midiáticos produzidos por viajantes, escritores ou autoridades provinciais brancas, quanto pelas numerosas análises de fontes autorais de escravizadas e libertas negras, mapeadas a partir de trabalhos mais recentes do campo histórico. Estando inserida nas Ciências Sociais, em especial na Sociologia, de que modo se deu sua aproximação e escolha dos referenciais historiográficos? Considerando suas ponderações acerca das relações ora de invisibilização completa ora de desconsideração das subjetividades, agenciamentos e vivências coletivas estruturadas pelas mulheres negras no âmbito das Ciências Sociais, e o teor semelhante a esse observado nos referenciais historiográficos hegemonicamente divulgados (exposto, por exemplo, pelo fato de as obras da historiadora Beatriz Nascimento estarem sendo publicadas em maior escala somente agora, há quase três décadas de sua morte), como você percebe as possíveis imbricações entre as formulações da História e da Sociologia? Há algum tipo de tensionamento evidente?

[Taís de Sant'Anna Machado]: A intenção de aproximação do campo da História esteve no horizonte desde o início da pesquisa de doutorado, mas 
encontrei as ferramentas que precisava quando cursei "A história intelectual de mulheres negras" com a professora Emily A. Owens (2015) do Departamento de História da Brown University, durante o Doutorado Sanduíche, e o curso "Construtores da liberdade: comunidades, lutas e identidades negras no Brasil do século XIX”, organizado pelo pesquisador Rafael Galante, da USP, com uma série de intelectuais brasileiros que têm proposto novos olhares historiográficos atentos à agência da população negra. Assim, pude entrar em contato com um referencial historiográfico feminista negro que tem se construído nos Estados Unidos nas duas últimas décadas, como nos trabalhos das historiadoras Saidiya Hartman (2021, 2020) e Marisa Fuentes (2016), além das referências sobre a história de mulheres negras brasileiras, como Juliana Barreto Farias (2012), Giovanna Xavier e Flávio Gomes (2012). O estudo dessas obras me ensinou a desenvolver outro olhar sobre os registros de arquivo de cozinheiras negras que encontrei ao longo do trabalho - como a carta de Esperança Garcia (SOUSA, 2020: 21-42) ou os registros dos diários de Carolina Maria de Jesus (2014, 1993). Na maneira como construí a tese, é evidente que acredito que existem muitas imbricações possíveis entre Sociologia e História (havendo até mesmo o campo da Sociologia Histórica), mas, sendo bastante honesta, as tensões disciplinares entre os dois campos, que certamente existem, não estiveram tanto em minhas preocupações durante o processo de escrita. Isto tem a ver com a escolha metodológica de entender a necessidade de uma certa indisciplina em minha pesquisa, inspirada em outros trabalhos atentos à complexidade da agência de pessoas negras, 
Cadernos de Clio, Curitiba, v. 12, $\mathrm{n}^{\circ} .1,2021$

como o de Christina Sharpe: "Devemos nos tornar indisciplinados. O trabalho que fazemos exige novos modos e métodos de pesquisa e ensino; novas formas de entrar e sair dos arquivos da escravidão (...) Penso que é isso que [Dionne] Brand descreve em A Map to the Door of No Return como uma espécie de conhecimento enegrecido, um método não científico, que vem de observar que onde se está é relativo à Porta do Não Retorno e àquele momento de ruptura histórica e contínua. Com isso como base, tenho tentado articular um método de encontrar um passado que não é passado. Um método semelhante a uma "sessão com”, uma reunião e um acompanhamento de fenômenos que afetam desproporcional e devastadoramente os povos negros em qualquer lugar que estejamos. (...) Interessa-me como imaginamos formas de conhecer esse passado, além das ficções do arquivo, mas não só isso. Também me interessa as maneiras como reconhecemos as muitas manifestações dessa ficção e desse excesso, desse passado ainda não passado, no presente" (SHARPE, 2016: 17-18, tradução própria).

[E. E.]: Um dos tópicos de seu trabalho é dedicado a contar a história por trás da elaboração da capa atribuída a ele (retrato de fundo azul, piso em madeira e com a ilustração de quatro mulheres negras em diferentes trajes, conforme imagem em ANEXO I). Geralmente, vemos produções acadêmicas sendo divulgadas apenas em sua versão de formatação oficial, isto é, com uma folha inicial organizada sob as normatizações da ABNT, sem que se vinculem imagens ou uma estética artística própria ao trabalho, 
Cadernos de Clio, Curitiba, v. 12, $n^{\circ} .1,2021$

mesmo que, em seus conteúdos, as obras trabalhem de maneira contundente com dispositivos audiovisuais. No âmbito da sua tese, o quadro escolhido parece assumir uma carga de significado bastante expressiva, denotando certas intencionalidades na representação trazida, em correlação com o que você menciona sobre os impactos afetivos e existenciais legados pela pesquisa testemunhal com um grupo diverso de trabalhadoras negras do ramo alimentício. Em vista disso, poderia explicar quais as motivações que a levaram a ter uma capa imagética específica para a tese, o processo de elaboração dela e a importância desempenhada pelo material?

[Taís de Sant'Anna Machado]: O objetivo de construir uma capa para a tese está na percepção de que a história de cozinheiras negras foi intensamente invisibilizada, e por isso a visualidade pode se tornar uma ferramenta tão importante. Vale dizer que a arte da capa é de autoria da artista negra mineira Daiely Gonçalves ${ }^{5}$, para quem apresentei diversas referências visuais que fui encontrando em minhas pesquisas de arquivo - entre mulheres anônimas e figuras conhecidas -, de modo que ela pudesse construir esse trabalho autoral belíssimo e sensível. A maneira como as mulheres estão dispostas na imagem também tem a intenção de representar a conexão das experiências de vida e de trabalho de cozinheiras negras em diferentes períodos históricos e temporalidades, entendendo que o racismo

${ }^{5} \mathrm{O}$ portfólio e os meios de contato da artista podem ser acessados através da página: https://linktr.ee/daielygoncalves. 
anti-negritude, o sexismo e o classismo se atualizam e se sofisticam ao longo do tempo.

[E. E]: Na área de História, apesar de as discussões sobre a importância de se expandir pesquisas para além de documentações oficiais estar em curso desde a primeira metade do século passado, ainda se notam certas resistências conservadoras ao uso de fontes menos convencionais, como as cinematográficas, por exemplo. Essa situação se estende à modalidade de relatos, que constituem o campo da História Oral e sofrem descreditações por terem ramificações pronunciadas com a esfera memorial. Em sua pesquisa, sobressai-se a prática de realização de 10 entrevistas que, como você detalha, tomaram lugar em um escopo variado de cidades e visaram a um rol também diverso de entrevistadas, contatadas por meios múltiplos que envolveram inclusive as redes sociais. Considerando esses elementos, poderia comentar um pouco sobre como se deu o processo das entrevistas, em relação à viabilização das viagens, à seleção das mulheres que seriam entrevistadas e ao impacto das conexões propiciadas pelas redes sociais como o Twitter? Tendo por base o panorama mencionado acerca da área de História Oral, em quais termos você avalia a receptividade de avaliadores e de pares acadêmicos à metodologia de construção de seu objeto de estudo parcialmente por meio das entrevistas, houve algum tipo de invalidação do trabalho? Por último, notamos que o conjunto de materiais coletados parecem exercer uma função memorial relevante, contornando anonimatos e desvalorizações de trajetórias individuais e 
coletivas de cozinheiras negras. A partir disso, gostariamos que pautasse algumas de suas reflexões acerca dos horizontes de preservação memorial das trajetórias e narrativas das mulheres negras no Brasil.

[Taís de Sant'Anna Machado]: No campo da Sociologia, o uso de entrevistas é bastante comum e, desde a graduação, somos orientados sobre os diversos usos dessa técnica de pesquisa, então não é costumeiro haver uma invalidação do trabalho por essa razão. Quanto à necessidade de preservação memorial das trajetórias e narrativas de mulheres negras no Brasil, esse é um dos grandes objetivos da tese. Um dos participantes da banca de defesa definiu meu trabalho como um olhar sobre a história do Brasil partindo da cozinha - e isso me alegrou por pensar que essa é uma das contribuições que pretendia dar com esse trabalho. A história de mulheres negras ainda pede muitas escrituras, especialmente uma que considere seu olhar como fundamental para entender a sociedade. A análise sócio-histórica que ofereço na tese atesta como cozinheiras negras são analistas perspicazes da sociedade em que vivem, uma característica essencial para garantir a sua sobrevivência e a dos seus. Um projeto memorial que trate desses registros em suas nuances e complexidades é essencial para uma produção de conhecimento mais completa, mas não só: para contribuir para a construção de um mundo mais justo, que considere as contribuições e necessidades de mulheres negras.

\section{Referências}


COLLINS, Patricia Hill. Pensamento feminista negro: conhecimento, consciência e política do empoderamento. 1 ed. São Paulo: Boitempo, 2019.

DZIDZIENYO, Anani. A África vista do Brasil, Afro-Ásia, n. 10-11, 1970.

FARIAS, Juliana Barreto. Mercados Minas: africanos e ocidentais na Praça do Mercado do Rio de Janeiro (1830-1890). 2012. Tese (Doutorado em História) - Universidade de São Paulo, São Paulo, 2012.

FUENTES, Maria J. Dispossessed Lives: Enslaved Women, Violence, and the Archive. Pennsylvania: University of Pennsylvania Press, 2016.

GONZALEZ, Lélia. A mulher negra na sociedade brasileira: uma abordagem político-econômica. In: - Primavera para as rosas negras. 1 ed. São Paulo: União de Coletivos Pan Africanistas (UCPA), 2018.

HARTMAN, Saidiya. Perder a mãe: uma jornada pela rota atlântica da escravidão. Rio de Janeiro: Bazar do Tempo, 2021.

.Vênus em dois atos, Revista ECO-Pós, v. 23, n. 3, p. 12-33, 2020.

JESUS, Carolina Maria de. Diário de bitita. São Paulo: Editora SESI-SP, 2014.

1993.

- Quarto de despejo: diário de uma favelada. [S.1.]: Editora Ática,

MACHADO, Taís de Sant'Anna. “Um pé na cozinha”: uma análise sócio-histórica do trabalho de cozinheiras negras no Brasil. 2021. $305 \mathrm{f}$. Tese (Doutorado em Sociologia) - Universidade de Brasília, Brasília, 2021.

OWENS, Emily Alissa. Fantasies of Concent: Black Women's Sexual Labor in 19th Century New Orleans. Doctoral Dissertation - Graduate School of Arts \& Sciences, Harvard University, 2015. 
PERRY, Keisha-Khan Y. Black women against the land grab: the fight for racial justice in Brazil. 1 ed. Minneapolis: University of Minnesota Press, 2013.

SHARPE, Christina. In the Wake: On Blackness and Being. Durham: Duke University Press, 2016.

SOUSA, Maria Sueli Rodrigues de. Direito e resistência: Esperança Garcia, desigualdade e igualdade como fundamento da nação. In: MARTINS, Tereza Cristina Santos.; SILVA, Nelmires Ferreira da. (Org.). Racismo estrutural, institucional e Serviço Social. São Cristóvão: Editora UFS, 2020.

TELLES, Lorena Féres da Silva. Libertas entre Sobrados: Mulheres Negras e Trabalho Doméstico em São Paulo. 1 ed. São Paulo: Alameda Editorial, 2013.

WALLACE-SANDERS, Kimberly. Mammy - a century of race, gender and southern memory. 1 ed. Ann Arbor: University of Michigan Press, 2008.

XAVIER, Giovana; FARIAS, Juliana Barreto; GOMES, Flávio. Mulheres negras no Brasil pós-escravista e do pós-emancipação. 1 ed. São Paulo: Selo Negro Edições, 2012. 